\title{
The effect of prenatal classes on pregnant women when deciding the delivery type and coping with labor pain
}

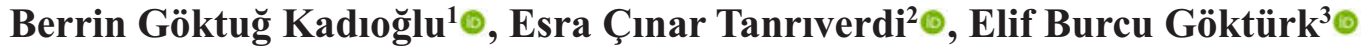 \\ ${ }^{1}$ Department of Obstetrics and Gynecology, University of Health Sciences, Erzurum Region Training and Research Hospital, Erzurum, \\ Turkey \\ ${ }^{2}$ Department of Medical Education, Atatürk University School of Medicine, Erzurum, Turkey \\ ${ }^{3}$ Department of Obstetrics and Gynecology, Erzurum Nenehatun Maternity Hospital, Erzurum, Turkey
}

\section{ABSTRACT}

Objectives: The purpose of the study is to determine the impacts of the prenatal classes on pregnant women while determining the type of delivery and coping with pain during delivery.

Methods: This study is descriptive. It involves analysis of 247 participants that were selected as samples from a known population of 653 pregnant women who participated in prenatal classes of our hospital. The prenatal classes took place for 3 weeks and 16 hours in total. They filled the forms regarding the class activities before and after the class. The data were evaluated by using SPSS 16.0 packaged software.

Results: The mean age of the pregnant women was $27.50 \pm 4.60$ years. The women, who had their first pregnancy, were $73.3 \%$. Before the class, $62.8 \%$ declared that they were planning to have a vaginal delivery. The ones, who stated that they were afraid of pain, were $78.9 \%$. In interviews after the classes, $89.5 \%$ of the participants stated that the classes affected their choice of delivery type. The rate of participants that found classes relieving for their anxiety and concerns was $94.70 \%$. The rate of participants that had a vaginal delivery was $81.80 \%$. The influence of the prenatal classes while determining the type of delivery was statistically significant. ( $p<0.001$ by Mc Nemar test).

Conclusions: Participation with the prenatal class removes the anxiety of the pregnant women, encourages them to have vaginal delivery and contributes to decreasing the rate of cesarean sections.

Keywords: Prenatal class, pain during delivery, cesarean section

$\mathrm{T}$ he pregnancy carries risks for the mother and the baby so that it creates concerns even if they are considered as physiological by society [1]. Parallel to the advancement in healthcare, the pregnant women become more interested in getting informed about the pregnancy and delivery [2]. The classes, which are done to ensure a healthy pregnancy, to inform and answer the questions, to educate about the delivery and postpartum period, are important to reduce the cesarean section rates that are gradually increasing in the world and in our country [3]. The pregnant women choose to have a cesarean section particularly because they are concerned that they will not be able to deal with the pain $[4,5]$. Acquiring information from competent people on pregnancy and delivery increases their confidence and provides active participation during delivery as they become aware of their body [6]. Prenatal classes that started in the 1930 s continue to grow becoming more disciplined. In our hospital, this program is implemented as a pregnant school by ex- 
panding education, counseling and exercise programs related to pregnancy, delivery and postpartum periods and by further improving the physical properties of the environment [7]. Prenatal class program is conducted in order to raise awareness of mother candidates and to enable them to take an active role in birth and baby care.

The purpose of the study is to determine the impacts of the prenatal classes on pregnant women, who participated the prenatal classes that have been given in our hospital since June 2015, while determining the type of labor and coping with labor pain.

\section{METHODS}

This study is descriptive. The population is 653 pregnant women who participated in prenatal classes of our hospital and earned their certificate between in June 2015-December 2018. The minimum sample size is calculated as 242 per sampling formula for cases with a known population. As some of the participants might be excluded from the study, 260 individuals were selected from a simple table of random numbers. The actual sample size of this study was 247 . The responses of these 247 participants were evaluated. Within the rules of admission to the prenatal classes, all participants filled a consent form both for attending the classes and for use of their data in this study.

Data were collected by "data collection form before the prenatal class" (1st part is composed of 8 questions on socio-demographic properties, 2nd part is composed of 26 questions on obstetric history), "data collection form after the prenatal class" that had 5 questions and "prenatal class training activity questions form" that had 21 questions.

The pregnant women, particularly the ones that were followed in polyclinics of our hospital or the ones that we were able to reach, who fulfilled the requirements of participation, were accepted to the class. After their heart rates were detected, they were invited to the class regardless of their week in pregnancy. The ones that had closer weeks in pregnancy with each other were put in the same group. The ones with medical conditions that would prevent their attendance to the classes and exercises or the ones that had risky pregnancies were not admitted to the class. The ones that satisfy all the criteria but previously had a cesarean section were not included. The classes took place during 2 half days for 3 weeks and 16 hours in total. The subjects were determined by the Republic of Turkey Ministry of Health that was centered on vaginal delivery. The subjects include anatomical and physiological changes during pregnancy, diet, frequently encountered problems, overall care, exercises, vaginal delivery, newborn care and breastfeeding. The participants that attended all classes were awarded a certificate. In our study, the participants who got certificates were included.

For the study, permission of the clinical research ethics committee of the University of Health Sciences, Erzurum Regional Training and Research Hospital was obtained. (Decision No: 17.09.2018/14-147).

\section{Statistical Analysis}

The data is analyzed by SPSS 16 packaged software and Mc Nemar test for descriptive statistics such as counts, percentages, mean values and standard deviation. The significance level is determined to be $p$ - value smaller than 0.05 .

\section{Table 1. Socio-demographic properties}

\begin{tabular}{lccc}
\hline Property & & n & \% \\
\hline Age & $<25$ & 69 & 27.9 \\
& $25-35$ & 165 & 66.8 \\
\hline Education & $>35$ & 13 & 5.3 \\
& Illiterate & 1 & 0.4 \\
& Elementary school & 14 & 5.7 \\
& Middle school & 21 & 8.5 \\
\hline & High school & 58 & 23.5 \\
\hline Employment & University and & 153 & 61.9 \\
& postgraduate & & \\
\hline Health insurance & Yes & 71 & 28.7 \\
\hline Income & No & 176 & 71.3 \\
\hline & Yes & 240 & 97.2 \\
\hline Usage of internet & No & 7 & 2.8 \\
\hline and social media & High & 57 & 23.1 \\
\hline & Mediocre & 141 & 57.1 \\
\hline & Low & 49 & 19.8 \\
\hline & No & 228 & 92.3 \\
\hline & & 19 & 7.7 \\
\hline
\end{tabular}




\section{RESULTS}

The socio-demographic information of the pregnant participants was as follows: Ages ranged between 19 and 40 (mean $27.50 \pm 4.60$ ) years, 61.9\% was college graduate, $28.7 \%$ was currently employed. The participants that indicated their income levels as mediocre (income equals to expenses) were $57.1 \%$. Almost all of them had health insurance (97.2\%). The participants that used the Internet and social media were $92.3 \%$ (Table 1). The results from their obstetric history were as follows: For $73.3 \%$, it was the first pregnancy; $13.8 \%$ had one and $12.9 \%$ had two or more deliveries with living children. Most of the participants $(60.3 \%)$ were less than 28 -weeks pregnant. The ones that planned the type of delivery were $65.6 \%$ whereas $34.4 \%$ stated that they did not have any plans (Table 2).

When the participants were asked whether they got any prenatal classes before, 9.7\% answered positive and $8.5 \%$ of the ones, who got classes before, took them in Family Health Centers (Table 3). The percentage of participants, who stated that they were afraid of pain during pregnancy, was $78.9 \%$. The percentage of participants, who indicated that they did not have any plans to cope with pain during delivery, was $5.3 \%, 41.7 \%$ stated that walking and moving would be the most efficient way to cope with the pain (see Table 3).

In the interviews after the classes, $100 \%$ of the participants stated that they were satisfied with the classes; $89.5 \%$ stated that the classes affected their choice of delivery type; $94.7 \%$ of them said that prenatal classes contributed to relieve their anxiety and concerns related to the delivery (Table 4$)$. This was statistically very significant $(p<0.001$ by McNemar test). The rate of vaginal delivery was $81.8 \%$.

Before the classes, $62.8 \%$ of the participants indicated that they preferred vaginal delivery. After the classes, this rate significantly increased to $97.2 \%(p<$ 0.001 by McNemar test) (Fig. 1).

\section{DISCUSSION}

Labor and pain during delivery have always been scary for the woman whose fear and anxiety were built up by labor stories and experiences of others [8].
Table 2. Pregnancy history

\begin{tabular}{|c|c|c|c|}
\hline Questions & Responses & $\bar{n}$ & $\%$ \\
\hline \multirow{4}{*}{$\begin{array}{l}\text { Number of } \\
\text { pregnancies }\end{array}$} & First & 181 & 73.3 \\
\hline & 2 & 34 & 13.8 \\
\hline & 3 & 22 & 8.9 \\
\hline & 4 and more & 10 & 4.0 \\
\hline \multirow[t]{4}{*}{ Number of deliveries } & 0 & 190 & 76.9 \\
\hline & 1 & 34 & 13.8 \\
\hline & 2 & 17 & 6.9 \\
\hline & 3 and above & 6 & 2.4 \\
\hline \multirow{4}{*}{$\begin{array}{l}\text { Week of pregnancy } \\
\text { (during labor) }\end{array}$} & $\leq 28$ & 149 & 60.3 \\
\hline & $29-36$ & 79 & 32.0 \\
\hline & $37-40$ & 19 & 7.7 \\
\hline & $>41$ & 0 & 0 \\
\hline \multirow{2}{*}{$\begin{array}{l}\text { Problems } \\
\text { encountered during } \\
\text { pregnancy }\end{array}$} & Yes & 71 & 28.7 \\
\hline & No & 176 & 71.3 \\
\hline \multirow[t]{2}{*}{ Pregnancy method } & Spontaneous & 237 & 96.0 \\
\hline & By treatment & 10 & 4.0 \\
\hline \multirow[t]{3}{*}{ Planned labor type } & Vaginal & 155 & 62.8 \\
\hline & $\begin{array}{l}\text { Cesarean } \\
\text { section }\end{array}$ & 7 & 2.8 \\
\hline & No plan & 85 & 34.4 \\
\hline \multirow[t]{2}{*}{ Labor type } & Vaginal & 202 & 81.8 \\
\hline & $\begin{array}{l}\text { Cesarean } \\
\text { section }\end{array}$ & 45 & 18.2 \\
\hline
\end{tabular}

Advancement of technology and developing world view increase the desire and opportunity to reach knowledge [2]. Prenatal classes provide easy information and skills on pregnancy and delivery by interactive exercises [9].

With the help of the Internet, information on pregnancy and delivery becomes more accessible [10]. The studies suggest that the pregnant women that had higher education and worked in healthcare had a higher rate of attending prenatal classes [11]. In our study, the highest percentage of the participants was college graduates. Although the pregnant women are 
Table 3. The evaluation before the class

\begin{tabular}{llcc}
\hline Questions & Responses & n & \% \\
\hline Did you take prenatal classes before? & Yes & 24 & 9.7 \\
& No & 223 & 90.3 \\
\hline How did you decide to attend the classes? & My doctor suggested & 21 & 8.5 \\
\hline & Nurse & 118 & 47.8 \\
& Poster, brochure, internet & 22 & 8.9 \\
\hline & Other & 77 & 31.2 \\
\hline Why did you participate the classes? & Other & 9 & 3.6 \\
\hline & To learn about the process & 60 & 24.3 \\
\hline & To learn the exercises & 5 & 2.0 \\
\hline Are you afraid of the pain during labor? & To learn easy delivery methods & 22 & 8.9 \\
\hline In your opinion, what is the best way to cope with & To reduce my anxiety & 20 & 8.1 \\
\hline pain during labor? & All & 140 & 56.7 \\
\hline & Yes & 195 & 78.9 \\
\hline & No don't know & 52 & 21.1 \\
\hline & & 0 & 0 \\
\hline Do you have any plan to cope with pain during labor? & Yes & & \\
\hline & Medication & 17 & 6.9 \\
\hline & Listening to music & 2 & 0.8 \\
\hline & Massage & 49 & 19.8 \\
\hline & Walking & 103 & 41.7 \\
\hline & Warm shower & 49 & 19.8 \\
\hline & Other & 27 & 10.9 \\
\hline
\end{tabular}

Table 4. Prenatal class activity questions and changes in knowledge and behavior

\begin{tabular}{|c|c|c|c|c|}
\hline \multirow[t]{3}{*}{ Questions } & \multicolumn{4}{|c|}{ Responses } \\
\hline & \multicolumn{2}{|c|}{ Yes } & \multicolumn{2}{|c|}{ No } \\
\hline & $\mathrm{n}$ & $\%$ & $\mathrm{n}$ & $\%$ \\
\hline Did you gain new information and skills? & 247 & 100.0 & 0 & 0 \\
\hline $\begin{array}{l}\text { Did your fear and anxiety regarding the } \\
\text { labor decrease? }\end{array}$ & 234 & 94.7 & 13 & 5.3 \\
\hline Did your confidence increase? & 237 & 96.0 & 10 & 4.0 \\
\hline $\begin{array}{l}\text { Would you consider vaginal delivery if } \\
\text { there are no complications? }\end{array}$ & 240 & 97.2 & 7 & 2.8 \\
\hline $\begin{array}{l}\text { Did class have any influence on you to } \\
\text { change your decision on delivery type? }\end{array}$ & 221 & 89.5 & 26 & 10.5 \\
\hline Are you satisfied with the training? & 247 & 100.0 & 0 & 0 \\
\hline
\end{tabular}




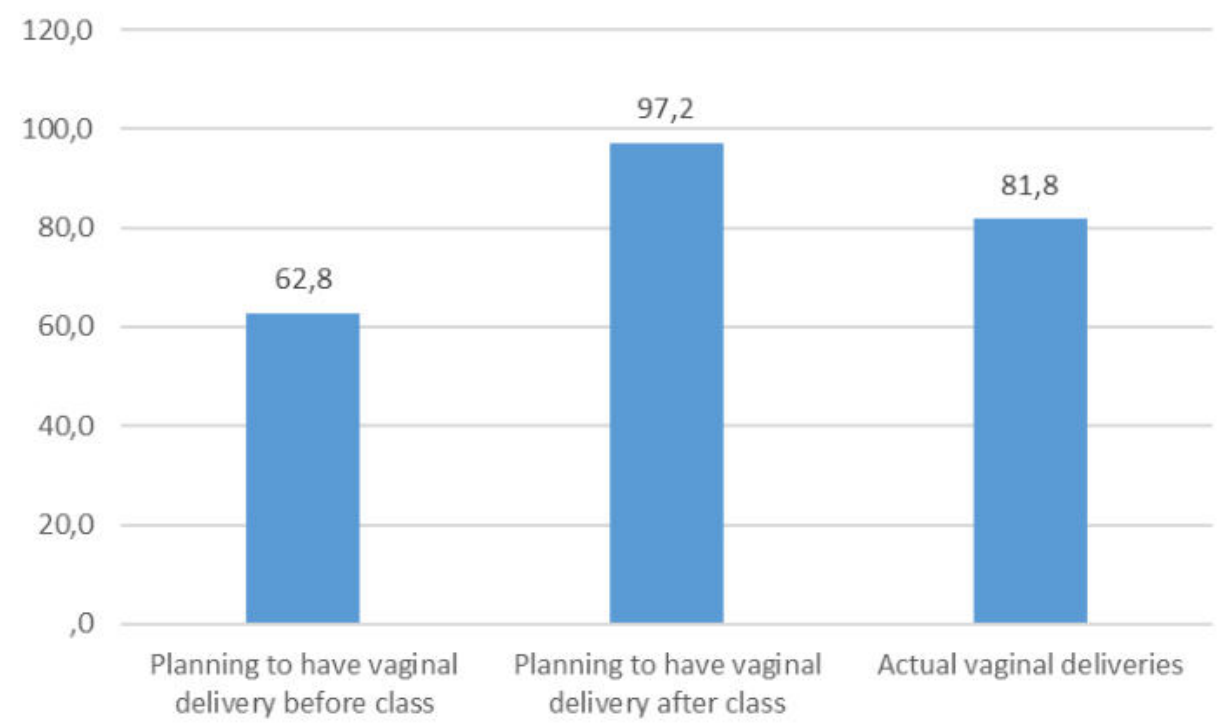

Fig. 1. Vaginal delivery rates after taking the class.

invited to the classes regardless of their education level, the higher demand by pregnant women with higher education indicates that we should focus more on the less educated. The rate of women that were working was stated as $37.10 \%$ by Turgut et al. [12] and in our study, the rate was $28.7 \%$. The same study stated that women with their first pregnancy participated more $(72.9 \%)$ and the results were similar in our study $(73.3 \%)$. The participants that were actively using the Internet and social media were $92.3 \%$. In a study carried out in Sweden, the rate was reported as $95 \%$ [13]. In our study, $57.1 \%$ of the participants declared their income to be mediocre (income equals the expenses), which was similar to the results from the study of Okumuş et al. [14].

The biggest concern of the pregnant about the delivery is not being able to cope with the pain, which unnecessarily leads them to opt for cesarean section [4]. In order to reduce the labor pain, in addition to the traditional methods, non-pharmacological methods are applied in health centers. Relaxation therapies such as music, aromatherapy, acupuncture, acupressure, yoga, hypnosis or dermatological stimulation methods such as massage (especially back and effleurage), intradermal water injection, transcutaneous electric neuron stimulation, and heat are among the applications [15]. In our study, before the classthe pregnant women were asked in a data collection form how they planned to deal with labor pain and then which of the choices that we offered they would choose. Most of them (94.7\%) stated that they had a plan and they thought walking/moving would reduce the pain the most. In another study, breathing exercises were preferred the most by the participants [12]. Before the class, the participants were hesitant about the vaginal delivery but after the class, the rate of preference for vaginal delivery increased to $97.2 \%$. In their postpartum histories, it is detected that $81.8 \%$ of them had a vaginal delivery. In another study, antenatal education is reported to be significantly effective to come over the fear [16]. In a study by Masoumi et al. [6] no significant change between the ones, who took the class and who did not, was reported and the rate of cesarean section was still high. The pregnant women prefer cesarean section because of the fear of being alone and the negative experiences that they heard from the family members, close friends, their circle and social media. One-to-one communication with the participants and the introduction of the emergency and delivery rooms of our hospital during the classes made them feel safe and encouraged them to have a vaginal delivery. Occasionally, nurse midwives took the same classes in order to be able to empathize and communicate with the pregnant women. This application removed the prejudice of the pregnant women about delivery and the care providers in the delivery room by ensuring a hospitable environment. Similarly, the approach of the nurses towards the patients was positively affected. 


\section{CONCLUSION}

Labor requires physical and psychological cooperation of the mother with the healthcare providers. Participation with the prenatal classes reduces the concerns of the prospective mothers, prevents misguidance due to second-hand information, provides a fun environment where they feel secure and get educated with their peers. The participants are also encouraged by the certificates that they earn at the end to complete the classes where they are incentivized to have vaginal delivery reducing the rate of cesarean section.

\section{Authors' contribution}

$\mathrm{BGK}=$ Data collection and literaturere view, analysis, writing; $\mathrm{EÇT}=$ Data collection; and $\mathrm{EBG}=$ Data collection

\section{Conflict of interest}

The authors disclosed no conflict of interest during the preparation or publication of this manuscript.

\section{Financing}

The authors disclosed that they did not receive any grant during conduction or writing of this study.

\section{REFERENCES}

1. Petersen JJ, Paulitsch MA, Guethlin C, Gensichen J, Jahn A. A survey on worries of pregnant women- testing the German version of the Cambridge worry scale. BMC Public Health 2009;9:490.

2. WAPM. Declaration of Mother Rights in Barcelona 2001. Carrera JM, Cabero L, Baraibar R (eds). The Perinatal Medicine of then New Millenium: Proceedings of the 5th World Congress of Perinatal Medicine: Barcelona, Spain, September 23-27, 2001. 3. Karabel MP, Demirbaş M, İnci MB. [Changing rates of cesarean section in Turkey and in the world and probable causes]. Sakarya Med J 2017;7:158-63. [Article in Turkish]
4. Çakmak B, Arslan S, Nacar MC. [Opinions of women about cesarean delivery on maternal request]. Frrat Med J 2014;19:122-

5. [Article in Turkish]

5. Forstholm MM, Langhoff-Roos J, Lidegaard O. [Sectio at maternal request among nulliparous women]. Ugeskr Laeger 2010;172:2075-9. [Article in Danish]

6. Masoumi SZ, KazemiF, Oshvandi K, Jalali M, EsmaeiliVadanjani A, Rafiei H. Effect of training preparation for childbirth on fear of normal vaginal delivery and choosing the type of delivery among pregnant women in Hamadan, Iran: a randomized controlled trial. J Family Reprod Health 2016;10:115-21.

7. Letter of the General Directorate of Public Health dated 08.08.2018 and numbered 57536863-231.01.99-1109.

8. Hildingsson I, Haines H, Karlström A, Nystedt A. Presence and process of fear of birth during pregnancy-findings from a longitudinal cohort study. Women Birth 2017;30:e242-7.

9. Circular on the principles and procedures of prenatal classes and centers for counseling and preparation for delivery in health services. Republic of Turkey, Ministry of Health. October 2018. 10. Sayakhot P, Carolan-Olah M. Internet use by pregnant women seeking pregnancy-related information: a systematic review. BMC Pregnancy Childbirth 2016;16:65.

11. Şeker S, Sevil Ü. [Effect of childbirth education classes to postpartum maternal functional status and newborn perception]. Turkiye Klinikleri J Obstet Womens Health Dis Nurs-Special Topics 2015;1:1-9. [Article in Turkish]

12. Turgut N, Güldür A, Çakmakçı H, Şerbetçi G, Yıldırım F, Ender Yumru A, et al. [A study about knowledge level of pregnants that educated in pregnancy school]. JAREN 2017;3:18. [Article in Turkish]

13. Bijelke M, Martinsson AK, Lendahls L, Oscarsson M. Using the internet as a source of information during pregnancy - A descriptive cross-sectional study in Sweden. Midwifery 2016;40:187-91.

14. Okumuş H, Yenal K, Durgun Ozan Y, Öztürk E. [Scientific studies on childbirth education classes in Turkey: literature review]. Turkiye Klinikleri J Obstet Womens Health Dis NursSpecial Topics 2015;1:16-24. [Article in Turkish]

15. Mamuk R, Davas NI. [Use of nonpharmacologic relaxation and tactile stimulation methods in labor pain]. Şişli Etfal Hastanesi Tıp Bülteni 2010;44:137-44. [Article in Turkish] 16. Gökçe İsbir G, İnci F, Önal H, Yıldız PD. The effects of antenatal education on fear of childbirth, maternal self-efficacy and post-traumatic stress disorder (PTSD) symptoms following childbirth: an experimental study. Appl Nurs Res 2016;32:22732 . 